\title{
$A b$ initio molecular dynamics study of manganese porphine hydration and interaction with nitric oxide
}

\author{
Kevin Leung* and Craig J. Medforth \\ Sandia National Laboratories, \\ MS $1415 \& 1349$ Albuquerque, NM 87185 \\ * Email: kleung@sandia.gov
}

\begin{abstract}
We use $a b$ initio molecular dynamics (AIMD) and the DFT+U method to compute the hydration environment of the manganese ion in manganese (II) and manganese (III) porphines (MnP) dispersed in liquid water. These are intended as simple models for more complex water soluble porphyrins, which have important physiological and electrochemical applications. The manganese ion in $\mathrm{Mn}(\mathrm{II}) \mathrm{P}$ exhibits significant out-of-porphine plane displacement, and binds strongly to a single $\mathrm{H}_{2} \mathrm{O}$ molecule in liquid water. The $\mathrm{Mn}$ in $\mathrm{Mn}(\mathrm{III}) \mathrm{P}$ is on average coplanar with the porphine plane, and forms a stable complex with two $\mathrm{H}_{2} \mathrm{O}$ molecules. The residence times of these water molecules exceed $15 \mathrm{ps}$. The DFT $+\mathrm{U}$ method correctly predicts that water displaces NO from Mn(III)P-NO, but yields an ambiguous spin state for the $\mathrm{MnP}(\mathrm{II})-\mathrm{NO}$ complex.
\end{abstract}

\section{INTRODUCTION}

Porphyrins dispersed in water, coated on electrodes, and self-assembled into nanotubes have important applications as sensors $1,2, \underline{3}, \underline{4}, \underline{5}, \underline{6}$ and light-induced watersplitting and hydrogen production $\underline{\underline{7}}^{\underline{T}}$ Simple manganese porphyrins have been used as readily isolated experimental models for studying isoelectronic Fe(III) systems $\underline{8}$ Water soluble $\mathrm{Mn}(\mathrm{II})$ and $\mathrm{Mn}(\mathrm{III})$ porphyrins are particularly useful for detection of nitric oxide in cell tissues, and for distinguishing them from nitroxyl $\left(\mathrm{NO}^{-}\right.$ and HNO) compounds $\stackrel{2.3}{2}$ The relaxation processes of water soluble manganese and iron tetra-p-sulfonatephenyl porphyrins (TSPP) in NMR-compatible time scales have also been the subject of significant experimental studies. $.9 .10,11,12$

Despite their importance and widespread appearance in technological and biological settings, theoretical studies of transition metal porphyrins in aqueous media have been rare. This is in part due to the difficulty of modeling transition metal systems in general. In liquid water, bare divalent and trivalent first row transition metal ions are octahedrally 6-coordinated due to their partially filled 3d electron shells. While density functional theory (DFT) successfully predicts this feature, $\underline{13}$ sophisticated classical force fields with 3-body terms or quantum mechanics/molecular mechanics methods are needed to reproduce such hydration structures $\stackrel{14,15}{=}$ Transition metal porphyrins present an inherently interesting case. The molecular framework has an overall $-2 e$ charge resulting from the nitrogen atoms chelating the metal ions. How these chelated ions in porphyrins interact with water will be affected by the ion size, spin state, and porphyrin conformations.

Predicting the spin state of transition metal porphyrins presents a considerable theoretical challenge. While DFT is formally exact, practical implementations depend on the choice of the approximate exchange correlation func- tional, not all of which yield the correct spin state in transition metal complexes $\frac{16}{\underline{1}}$ This is particularly true for first row transition metal porphyrins $\frac{17}{17}$ It has been shown that the hybrid functionals like B3LYP 18 yields the correct stable high spin ground state for manganese (II) porphine $(\mathrm{Mn}(\mathrm{II}) \mathrm{P})$ and manganese (III) porphine

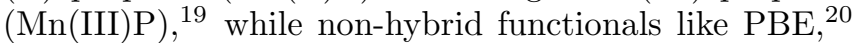
lacking a long range Hartree-Fock exchange component, predict the incorrect intermediate spin state for $\mathrm{Mn}$ (II)P. If constrained to the high spin state, PBE still yields a poor $\mathrm{Mn}(\mathrm{II}) \mathrm{P}$ molecular geometry $\frac{19.21}{1}$ However, hybrid functionals are far more expensive to apply than non-hybrids when applying periodic boundary conditions appropriate to condensed phase systems such as liquid water or metal surfaces. This problem has been circumvented 19 by applying the DFT $+\mathrm{U}$ method on the Mn 3d electrons $\stackrel{24}{=}$ The screened coulomb (" $U$ ") term in $\mathrm{DFT}+\mathrm{U}$ increases repulsion between electrons in lowspin, partially filled $d$-electron systems. In the approach used in Ref. 19, this term was parameterized using B3LYP spin splittings, and then the technique was applied to model $\mathrm{MnP}$ adsorbed on gold electrodes. The $\mathrm{DFT}+\mathrm{U}$ method has also proved accurate for Fe-based catalysts. 22

In this paper, we extend this previous work by conducting $\mathrm{DFT}+\mathrm{U}$ based $a b$ initio molecular dynamics (AIMD) simulations of $\mathrm{Mn}$ (II) and $\mathrm{Mn}(\mathrm{III})$ porphines in liquid water. Porphines not substituted with ionic side groups are mostly water-insoluble; our $\mathrm{MnP}$ molecules are intended as simple models for soluble porphyrins such as (MnTSPP) $, 9,10,11$ which are too large and computationally costly to simulate using AIMD ${ }^{23}$ The elucidation of the hydration environment of the metal ion in porphyrins is a prerequesite for studying the binding of additional ligands to the metal site of water-soluble porphyrins. AIMD hydration studies are potentially useful for modeling electrochemical half-reactions involving porphyrins; such calculations have already been performed 
for transition metal ions solvated in water $\stackrel{25}{\underline{2}}$ Our work also suggests that the metal ion hydration structure assumed in the analysis of NMR relaxation experiments on $\mathrm{Mn}(\mathrm{II}) \mathrm{TSPP}$ may need to be re-examined $\underline{9}^{9.10}$

Finally, we briefly consider the binding between $\mathrm{Mn}(\mathrm{II}) \mathrm{P}$ and $\mathrm{Mn}$ (III)P and nitric oxide (NO) in the gas phase and in water. Such complexes are classified according to the format $\{\mathrm{MNO}\}^{n}, \underline{\underline{26}}$ where $n$ is the number of metal $d$-electrons plus the unpaired electron contributed by NO. For $n \leq 6$, the M-NO bond should be short $(\sim 1.65 \AA)$, and the $\mathrm{M}-\mathrm{N}-\mathrm{O}$ angle should be $\sim 180^{\circ} . \underline{26}$ $\mathrm{Mn}(\mathrm{II})$ porphyrins are $n=6$ complexes, and X-ray structures of $\mathrm{Mn}(\mathrm{II})$ porphyrins ligated to $\mathrm{NO}$ indeed exhibit bond lengths and angles appropriate to $\{\mathrm{MNO}\}^{6}, \frac{8,27}{, 27}$ To our knowledge, no X-ray structures of NO-ligated $\mathrm{Mn}$ (III) porphyrins have been reported. Water soluble $\mathrm{Mn}$ (III) porphyrins are found not to complex with NO in aqueous conditions $\stackrel{4}{\sharp}$ As a result, electrochemical switching of the Mn oxidation state is potentially useful for detecting NO in cell tissues, and in distinguishing NO from $\mathrm{HNO}$, which binds to $\mathrm{Mn}$ porphyrins in both oxidation states.

Ideally, the same DFT method and/or functional can be used to predict all properties (energetics, structures, spectral properties) in all aqueous phase applications. There have been several reported successes of DFT treatment of Fe porphyrin-NO complexes ${ }^{28,29}$ These studies have focused on the molecular structures and vibrational properties, and not the binding energies between porphyrins and nitric oxide. In this work, we critically examine the effect of applying different exchange-correlation functionals on the spin state, molecular geometry, and binding energies of MnP-NO. We find that the DFT $+\mathrm{U}$ method successfully predicts that the $\mathrm{Mn}$ (III)P-NO complex dissociates in liquid water environments. However, we also conclude that neither DFT $+\mathrm{U}$ nor existing, widely used DFT functionals enjoy universal succcess in modeling nitric oxide ligation. This suggests that substantial functional development and refinement are necessary.

This paper is organized as follows. Section 2 describes the method used. Section 3 discusses the structure of water around the manganese ions in porphines. $\mathrm{MnP}-\mathrm{NO}$ binding is briefly described in Sec. 4, and Sec. 5 concludes the paper with further discussion.

\section{METHODS}

We conduct $a b$ initio molecular dynamics (AIMD) based on the DFT $+\mathrm{U}^{24}$ method implemented 30 in the VASP code version 4.6 $\frac{31}{1}$ Our VASP calculations apply the PBE exchange correlation functional, the projectedaugmented wave (PAW) method 32 and the standard VASP suite of PAW pseudopotentials. These include the Mn pseudopotential with pseudovalent $2 p$ electrons, and

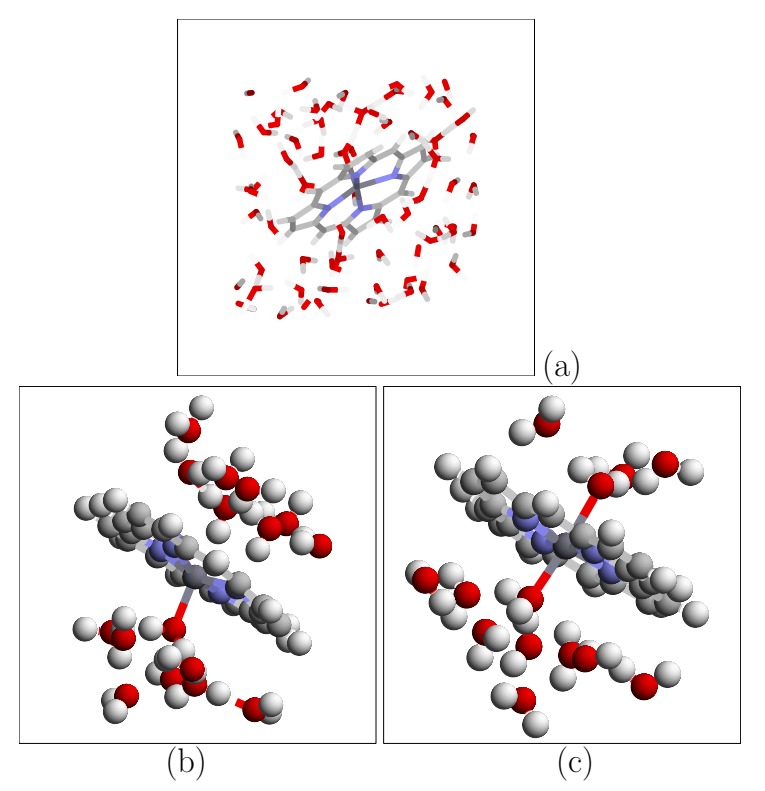

FIG. 1: Representative snapshots of (a) \& (b) Mn(II)P in water; (c) $\mathrm{Mn}$ (III)P in water. Except in panel (a), only the water molecules close to the $\mathrm{Mn}$ ion are depicted.

the oxygen, carbon, nitrogen, and hydrogen pseudopotentials with default energy cutoffs of 400, 400, 400, and $250 \mathrm{eV}$, respectively.

The Mn 3d orbitals are augmented with screened column (" $U$ ") and exchange (" $J ")$ terms of $U=4.2$ and $J=1.0 \mathrm{eV}$, respectively. These values have been shown to reproduce $\mathrm{Mn}$ (II)P high-spin/intermediate spin splittings predicted by the B3LYP functional, $\stackrel{19}{\stackrel{1}{2}}$ and predict the high spin $\mathrm{Mn}(\mathrm{III})$ porphyrin spin state observed in experiments. For more details, see Ref. 19 and the supporting information therein.

A plane wave energy cut-off of $400 \mathrm{eV}$ and a wavefunction convergent criterion of $10^{-5} \mathrm{eV}$ at each of the $0.5 \mathrm{ps}$ time step in the Born-Oppenheimer AIMD simulations. This work focuses on structural properties; hence, deuterium is substituted for all protons so that a larger time step can be used. A Nose thermostat with an estimated time constant of 20 fs maintains the average temperature at $\mathrm{T}=375 \mathrm{~K}$. With these parameters, the drift in total energy is 0.9 Kelvin per picosecond (i.e., $\sim 0.004$ $\mathrm{mHt} / \mathrm{atom} / \mathrm{ps}$ ) or less. This small energy drift is absorbed by the thermostat. Since the underlying PBE exchange correlation functional yields overstructured water and slow dynamics at $\mathrm{T}=300 \mathrm{~K}, \underline{33}$ the elevated temperature is necessary to obtain reasonable water structure and diffusion timescales. (See discussions in the next section.) These factors imply that the trajectories do not capture the real-time dynamics. Instead, the time dependence observed is used to confirm that the system has reached equilibrium, and it provides a time scale for 
thermal fluctuations under these simulation conditions. Trajectory lengths of at least 15 ps are used to collect statistics after equilibration runs have stabilized the potential energy.

The simulation cell is cubic with a linear dimension of $13.65 \AA$. The planar porphine molecule is inserted diagonally into the cell. This ensures that there are 5 to 6 layers of water molecules separating the periodically replicated $\mathrm{MnP}$ in the direction perpendicular to the porphine ring (Fig. 1). The water density in the cell is determined using a grand canonical Monte Carlo (GCMC) simulation, using the Towhee code, 34 SPC/E rigid water molecule force fields, $\stackrel{35}{,}$ and porphine force fields appropriate for $\mathrm{NiP}, 36$ which, with the exception of the metal ion parameters, should be reasonable for porphine atom$\mathrm{H}_{2} \mathrm{O}$ interactions. The $\mathrm{Mn}(\mathrm{II}) \mathrm{P}$ is held frozen in place in the GCMC simulations. It is found that 70 water molecules reside in the simulation cell. In the absence of $\mathrm{Mn}(\mathrm{II}) \mathrm{P}$, the $13.65 \AA^{3}$ cubic cell would contain 85 water molecules at $1.0 \mathrm{~g} / \mathrm{cc}$ density.

The water content for $\mathrm{Mn}(\mathrm{II}) \mathrm{P}-\mathrm{NO}$ is similarly determined using GCMC, resulting in $68 \mathrm{H}_{2} \mathrm{O}$ molecules in the simulation cell. The nitric oxide force field used is similar to that of Ref. 37. NO is essentially a hydrophobic molecule that interacts weakly with water.

All liquid phase pair correlation functions $g(r)$ are computed with a $0.1 \AA$ bin size, except that a $0.05 \AA$ bin size is used for pure liquid water.

B3LYP hybrid functional18 calculations of gas phase porphine complexes are performed using the program Gaussian 03. ${ }^{38}$ We first optimize the geometries using the LANL2DZ basis set. Then we switch to the more accurate $6-311+\mathrm{G}(\mathrm{d}, \mathrm{p})$ basis, and perform geometric optimization for 3 to 5 steps until the magnitude of each Cartesian component of the force on each atom is below $\sim 0.05 \mathrm{eV} / \AA$. (VASP gas phase calculations utilize a similar criterion for attaining optimal geometry.) We find that the $\mathrm{PBE} \mathrm{Mn}(\mathrm{II}) \mathrm{P}-\mathrm{H}_{2} \mathrm{O}$ binding energy computed using the $6-311+\mathrm{G}(\mathrm{d}, \mathrm{p})$ basis set, and that computed using the VASP code with plane wave basis sets, agree to within $24 \mathrm{meV}$.

\section{HYDRATION STRUCTURES OF MANGANESE PORPHINES}

First we consider the hydration structure of $\mathrm{Mn}(\mathrm{II}) \mathrm{P}$ in water. Simple, electrostatic-plus-Lennard Jones interactions between water and the porphine molecule are applied during the GCMC pre-equilibration simulation. These force fields predict that a $\mathrm{H}_{2} \mathrm{O}$ ligates to the metal ion on each side of the porphine plane, but the overall metal coordination structure is strongly distorted from the ideal octahedral geometry. Applying AIMD on this classical force field-generated starting configuration leads to substantial structural changes. We find that a 8 ps
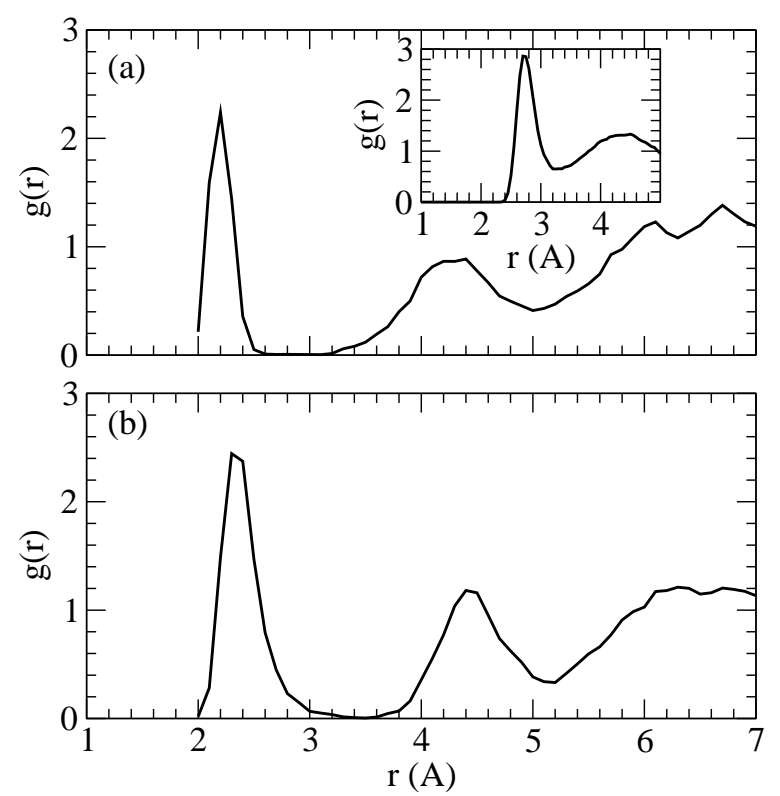

FIG. 2: Pair correlation functions $g(r)$ between the Mn ion and the oxygen sites of $\mathrm{H}_{2} \mathrm{O}$ for (a) Mn(II)P; (b) Mn(III)P. Inset: $g_{\mathrm{OO}}(r)$ for liquid water.

AIMD trajectory is needed to equilibrate the potential energy of the system. AIMD simulation of $\mathrm{Mn}(\mathrm{III}) \mathrm{P}$ in water is started from an equilibrated $\mathrm{Mn}(\mathrm{II}) \mathrm{P}$ configuration, and the potential energy of the system also converges to a plateau value within 8 ps. These long equilibration times help ensure that the statistics collected in the subsequent 15 ps production run are independent of initial conditions.

Figure 1a depicts a equilibrated hydration structure around $\mathrm{Mn}(\mathrm{II}) \mathrm{P}$ and confirms that there are several layers of water molecules buffering the Mn ion from its periodic image. This suggests that the hydration environment of the Mn ion adequately represents bulk water boundary conditions.

The representative configuration depicted in Fig. 1b focuses on $\mathrm{H}_{2} \mathrm{O}$ close to the $\mathrm{Mn}$ ion. Unlike the classical force field results, the $\mathrm{Mn}$ ion in $\mathrm{Mn}(\mathrm{II}) \mathrm{P}$ strongly binds to one rather than two $\mathrm{H}_{2} \mathrm{O}$ molecules. As discussed below, this can be related to the significant out of porphine plane motion exhibited by the $\mathrm{Mn}(\mathrm{II})$ ion. Figure 1c depicts $\mathrm{Mn}(\mathrm{III}) \mathrm{P}$ in water. $\mathrm{Mn}(\mathrm{III}) \mathrm{P}$ is on average coplanar with the porphine plane, and the Mn binds to two water molecules. These snapshots encapsulate this section's main results, which will be analyzed in some detail below.

The $\mathrm{Mn}(\mathrm{II})-\mathrm{H}_{2} \mathrm{O}$ pair correlation function $g_{\mathrm{Mn}-\mathrm{O}_{\mathrm{w}}}(r)$ is plotted in Fig. 2a, and it confirms the structure shown in Fig. 1b. The first peak in the $\mathrm{Mn}^{-\mathrm{O}_{\mathrm{w}}} g(r)$ integrates to 1.0 from $r=0$ to $r=3.0 \AA$, which is the first $g(r)$ minimum. The sharp peak and deep minimum clearly show that this water molecule is strongly bound to the 
$\mathrm{Mn}(\mathrm{II})$ ion. They are reminiscent of divalent cation $g(r)$ in liquid water $\stackrel{15.39}{=}$ In fact, over the entire 15 ps production run trajectory, the same water molecule remains bound to the Mn ion, although during the 8 ps equilibration trajectory, exchange of Mn first hydration shell water molecules with the bulk water region has occurred. Experimentally, the time scale for proton exchange that involves $\mathrm{H}_{2} \mathrm{O}$ bound to $\mathrm{Mn}(\mathrm{II})$ is known to be on the order $10^{-8}$ to $10^{-7} \mathrm{~s} . \underline{40}$

The inset to Fig. 2 depicts the pure water $g_{\mathrm{OO}}(r)$, computed using the PBE functional, 32 water molecules at $1.00 \mathrm{~g} / \mathrm{cc}$ light water density, and with the thermostat set at $\mathrm{T}=375 \mathrm{~K}$. It confirms that $\mathrm{PBE}$ water at $\mathrm{T}=375 \mathrm{~K}$ exhibits less overstructuring compared to $\mathrm{PBE}$ water at $\mathrm{T}=300 \mathrm{~K}$. For example, the $g_{\mathrm{OO}}(r)$ first peak exhibits a peak height of 2.9 density units at $\mathrm{T}=375 \mathrm{~K}$, which is in reasonable agreement with the value of 3.1 reported

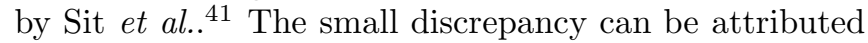
to statistical uncertainties and/or the use of different bin sizes. In contrast, at $\mathrm{T}=300 \mathrm{~K}$, this peak height exceeds 3.4 density units $\stackrel{42}{\frac{42}{2}}$ which is considerable larger than the experimental value. $\underline{\underline{41}}$ Our choice of $\mathrm{T}=375 \mathrm{~K}$ is thus reasonable for $\mathrm{MnP}$ hydration studies. While we have imposed a water density estimated using classical force fields and the GCMC method, we note that ion hydration structure appears insensitive to significant variations $(\sim 7 \%)$ in water density. $\underline{43}$

The stability of the single- $\mathrm{H}_{2} \mathrm{O}$ coordination structure of $\mathrm{Mn}(\mathrm{II}) \mathrm{P}$ is closely related to the significant $\mathrm{Mn}$ outof-plane motion. Figure 3a depicts the evolution of this displacement along the AIMD trajectory. Here, at each time step, we perform a least square-fit to generate a plane, $a x+b y+c x=1$, through the 4 nitrogen atoms, and $\delta_{\mathrm{Mn}}$ is obtained as the smallest distance between the $\mathrm{Mn}$ atom and this plane. On average, $\delta_{\mathrm{Mn}}$ is $0.48 \AA$ for $\mathrm{Mn}(\mathrm{II}) \mathrm{P}$ dispersed in water.

This large displacement can be related to the extremely flat out-of-plane Mn potential energy surface predicted by the DFT $+\mathrm{U}$ method for high spin $\mathrm{Mn}$ (II)P in the gas phase (Fig. 3b). Thus, upon binding to a ligand like a $\mathrm{H}_{2} \mathrm{O}$, the $\mathrm{Mn}$ ion is readily displaced out of the porphine plane. We find that this displacement is already $0.225 \AA$ for the $\mathrm{Mn}(\mathrm{II}) \mathrm{P}-\mathrm{H}_{2} \mathrm{O}$ complex in the gas phase, and this geometric feature explains the inability of the $\mathrm{Mn}$ ion to bind to a second $\mathrm{H}_{2} \mathrm{O}$ in a liquid water enviroment. Note that the out-of-plane displacement of the $\mathrm{Mn}$ ion is accompanied by only a small amount out-of-plane deformation of the porphine ring (approximately $0.1 \AA$ total deformation as determined by Normal Coordinate Structure Decomposition; see Table S1).

The out-of-plane Mn motion exhibits a flat potential energy surface because the high spin $\mathrm{Mn}(\mathrm{II})$ ion has a large effective size. The Mn-N distance in high spin $\mathrm{Mn}$ (II)P is predicted to be $2.09 \AA$, in good agreement with experiments $\underline{45,46}$ Thus, energetically, it is relatively unfavorable for $\mathrm{Mn}$ to fit in the center of the ion-chelating site of the porphine molecule. In contrast, the $\mathrm{Mn}$ (III) ion is smaller, with an Mn- $\mathrm{N}$ distance of $2.045 \AA$ in $\mathrm{MnClP}, \underline{19}$ and in isolated $\mathrm{Mn}(\mathrm{III}) \mathrm{P}$ strongly prefers to be coplanar with the porphine plane (Fig. 3c). In liquid water, this preference persists on average (Fig. 3a). This geometry allows effective binding to two ligands. Indeed the sharply peaked Mn-water first peak in $g(r)$ integrates to 2.0 , indicating two $\mathrm{H}_{2} \mathrm{O}$ are strongly ligated to the $\mathrm{Mn}$ ion. We do not observe exchange of the two $\mathrm{H}_{2} \mathrm{O}$ molecules bound to the $\mathrm{Mn}$ (III) ion with outer shell water during the 15 ps trajectory.

A search of the Cambridge Crystallographic Data Center (CCDC) yields 15 crystal structures of Mn porphyrins with one or more coordinated water molecules. The manganese ion exhibits the +3 oxidation state in all of them. The experimentally determined $\mathrm{Mn}-\mathrm{O}$ distances in the $\mathrm{Mn}(\mathrm{III})$ porphyrins $(\sim 2.2 \AA)$ correspond closely to the first peaks in the pair correlation functions in Fig. 2. The average calculated $\mathrm{Mn}-\mathrm{N}$ (porphine) distance in the high-spin $(m=2) \mathrm{Mn}(\mathrm{III}) \mathrm{P}\left(\mathrm{H}_{2} \mathrm{O}\right)_{2}$ energy minimized using the $\mathrm{DFT}+\mathrm{U}$ is $2.028 \AA$. This again agrees well with the $\mathrm{Mn}-\mathrm{N}$ (porphyrin) distances observed in $\mathrm{Mn}$ (III) porphyrin complexes with two axial water ligands (e.g., $\mathrm{Mn}(\mathrm{III}) \mathrm{TPP}\left(\mathrm{H}_{2} \mathrm{O}\right)_{2}(\mathrm{BPh})_{4}$, where the $\mathrm{Mn}-\mathrm{N}$ distance is $2.011 \AA) \stackrel{47}{\underline{4}}$ The porphine ring again shows very little non-planar distortion in either the $\mathrm{DFT}+\mathrm{U}$ gas phase structure of $\mathrm{Mn}(\mathrm{III}) \mathrm{P}\left(\mathrm{H}_{2} \mathrm{O}\right)_{2}$ (Table S2) or the crystal structure of $\mathrm{Mn}(\mathrm{III}) \mathrm{TPP}\left(\mathrm{H}_{2} \mathrm{O}\right)_{2}(\mathrm{Bph})_{4}$ (Table S3).

Gas phase B3LYP and DFT $+U$ calculations of the MnP- $\left(\mathrm{H}_{2} \mathrm{O}\right)_{2}$ complex (Fig. 4, Table I) provide more compelling evidence that $\mathrm{Mn}$ in $\mathrm{Mn}$ (II)P coordinates to only one water molecule. Both these methods predict that there are two nearly isoenergetic configurations for the high spin $\mathrm{Mn}(\mathrm{II}) \mathrm{P}-\left(\mathrm{H}_{2} \mathrm{O}\right)_{2}$ cluster (Fig. 4). The bidentate $\mathrm{Mn}$ (II) configuration, with the $\mathrm{Mn}$ ion residing in the porphine plane (Fig. 4a), is only slightly more stable than the one where $\mathrm{Mn}(\mathrm{II})$ is $\sim 0.4 \AA$ out-ofplane and one $\mathrm{H}_{2} \mathrm{O}$ is bound to $\mathrm{Mn}$ and the other coordinated to two nitrogen atoms (Fig. 4b). DFT $+\mathrm{U}$ predicts that the bidentate configuration is more stable by only $15 \mathrm{meV}$, while B3LYP predicts that they are equally stable. In contrast, with the system in either the intermediate or the high spin state, PBE predicts that the structure depicted in Fig. 4b is unstable and spontaneously relaxes to that shown in Fig. 4a. This emphasizes that there are fundamental differences between $\mathrm{DFT}+\mathrm{U}$ and PBE predictions for gas phase properties. These differences carry over into liquid phase AIMD simulations (Fig. 1a) favoring configurations similar to Fig. 4b. $\underline{48}$

Because of the slow exchange rate of Mn first hydration shell $\mathrm{H}_{2} \mathrm{O}$, it is important to check whether the $\mathrm{Mn}(\mathrm{II}) \mathrm{P}$ hydration structure we observe depends on the initial configurations. Thus, we start with a equilibrated $\mathrm{Mn}(\mathrm{III}) \mathrm{P}$ configuration, with two water molecules ligated to the Mn ion, and initiate a Mn(II)P AIMD simulation by adding one more electron to the simulation 


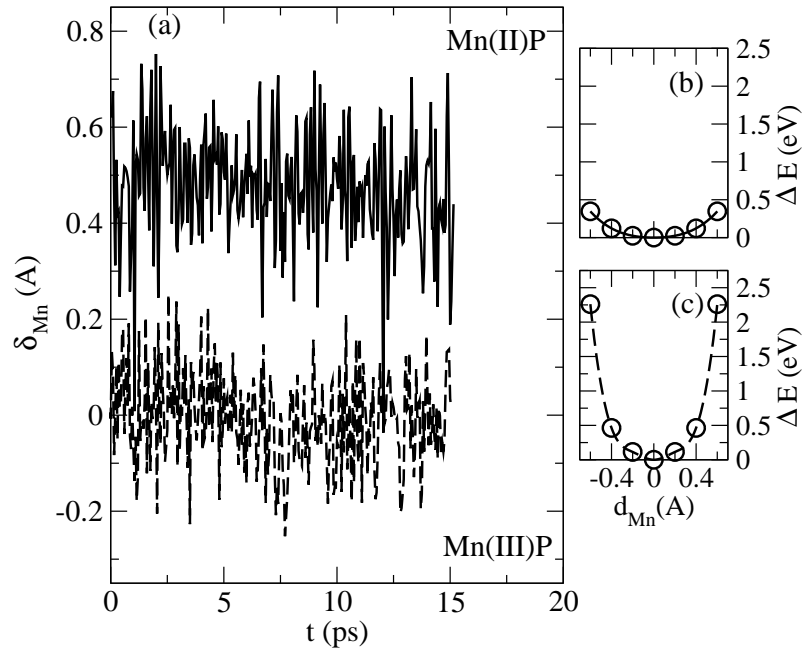

FIG. 3: (a) Out-of-porphine plane displacement of Mn ion, $\delta_{\mathrm{Mn}}$, over the AIMD trajectories for $\mathrm{Mn}(\mathrm{II}) \mathrm{P}$ and $\mathrm{Mn}(\mathrm{III}) \mathrm{P}$. (b) \& (c) Energies as functions of Mn out-of-plane displacement in the gas phase for $\mathrm{Mn}(\mathrm{II}) \mathrm{P}$ and $\mathrm{Mn}(\mathrm{III}) \mathrm{P}$, respectively The porphine ring is held fixed as the $\mathrm{Mn}$ is displaced.

cell. Within 1 ps, one of the first hydration $\mathrm{H}_{2} \mathrm{O}$ detaches itself, the Mn ion exhibits strong out-of-plane displacement, and the single $\mathrm{H}_{2} \mathrm{O}$ hydrated, 5-coordinated $\mathrm{Mn}(\mathrm{II})$ configuration is recovered. Thus, this $\mathrm{Mn}(\mathrm{II}) \mathrm{P}$ hydration structure is robust.

The predicted hydration structure of $\mathrm{Mn}(\mathrm{II}) \mathrm{P}$ might possibly resolve anomalies associated with paramagnetic relaxation behavior of $\mathrm{Mn}(\mathrm{II}) \mathrm{TPPS}$ in water $\underline{10,11}$ One model proposed in the NMR literature assumes a 6coordinated geometry, where 2 axial $\mathrm{H}_{2} \mathrm{O}$ molecules bind to the manganese ion in $\mathrm{Mn}(\mathrm{II}) \mathrm{TPPS}, \underline{11} \mathrm{In}$ contrast, AIMD predicts only one $\mathrm{H}_{2} \mathrm{O}$ in the hydration shell and a breaking of the inversion symmetry about the porphine plane, which now exhibits a $\mathrm{C}_{4 \mathrm{v}}$ symmetry. This suggests that the underlying assumptions of Ref. 11 regarding coordination to water may need to be re-examined. While paramagnetic relaxation behavior is complex, we propose that using a model with the $\mathrm{Mn}$ ion ligated to the AIMD predicted number of water molecules might improve agreement between experiments and the spinHamiltonian results used to inteprete NMR data $\underline{10,11}$

Figure 5 examines the hydration environment of the four nitrogen atoms surrounding the Mn ion. Integrating the $g_{\mathrm{N}-\mathrm{O}_{\mathrm{w}}}(r)$ to its first minimum $(3.8$ and $3.9 \AA$ for $\mathrm{Mn}(\mathrm{II}) \mathrm{P}$ and $\mathrm{Mn}(\mathrm{III}) \mathrm{P}$ respectively), we find that there are 1.76 and $2.83 \mathrm{H}_{2} \mathrm{O}$ in the hydration shell of each nitrogen atom. These spatial correlations partly originate from the one (two) $\mathrm{H}_{2} \mathrm{O}$ strongly coordinated to the $\mathrm{Mn}(\mathrm{II})(\mathrm{Mn}$ (III)) ion in the vicinity of the nitrogen atoms, and not from water-nitrogen hydrogen bonding. A N-H hydrogen bond typically exhibits a $g_{\mathrm{N}-\mathrm{H}_{\mathrm{w}}}(r)$ peak at $r \sim 1.8 \AA$, and a first minimum at $r \sim 2.5 \AA . \underline{49}$

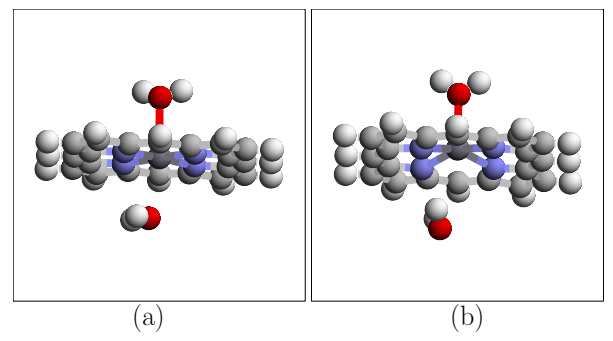

FIG. 4: Two configurations of $\mathrm{Mn}(\mathrm{II}) \mathrm{P}-\left(\mathrm{H}_{2} \mathrm{O}\right)_{2}$. DFT $+\mathrm{U}$ and B3LYp both predict that they are similar in energy, while PBE predicts that the structure in (b) is unstable.

Here, $g_{\mathrm{N}-\mathrm{H}_{\mathrm{w}}}(r)$ only exhibits small shoulders. Integrating $g_{\mathrm{N}-\mathrm{H}_{\mathrm{w}}}(r)$ to $r=2.5 \AA$ yields only 0.10 and 0.02 $\mathrm{H}_{2} \mathrm{O}$ in the first coordination shell per nitrogen atom for $\mathrm{Mn}(\mathrm{II}) \mathrm{P}$ and $\mathrm{Mn}(\mathrm{III}) \mathrm{P}$, respectively. We conclude that water interacts weakly with the nitrogen atoms.

Note that our AIMD trajectories impose a high spin configuration, known to be favorable in the gas phase $\underline{19}$ We have tested snapshots of the $\mathrm{Mn}$ (II)P trajectory to see if $\mathrm{Mn}(\mathrm{II}) \mathrm{P}$ in water favors spin states at variance from those predicted for the gas phase ground state. We invariably observe that the high spin configuration is favorable in these DFT $+\mathrm{U}$ generated AIMD snapshots when using the $\mathrm{DFT}+\mathrm{U}$ technique, in agreement with experiments on MnTSPP in water ${ }^{10,11}$ The intermediate spin state is favored in these snapshots when the PBE functional is used. Thus, dispersing $\mathrm{Mn}(\mathrm{II}) \mathrm{P}$ into liquid water does not alter the most stable spin state; for each functional used, the gas phase and aqueous phase spin state predictions are in agreement. This is expected because water is not a strong ligand.

\section{INTERACTIONS WITH NITRIC OXIDE}

In this section, we examine the interaction of $\mathrm{Mn}(\mathrm{II}) \mathrm{P}$ and $\mathrm{Mn}(\mathrm{III}) \mathrm{P}$ with NO. Ideally, the $\mathrm{DFT}+\mathrm{U}$ method, which predicts the correct $s=5 / 2$ spin state for $\mathrm{Mn}$ (II)P, can be used to treat MnP-NO binding in aqueous environments. We will show that $\mathrm{DFT}+\mathrm{U}$ appears to yield reasonable binding energies. Neither DFT $+U$ nor B3LYP necessarily predicts the correct spin states for the MnP-NO complexes. However, since the energies of different spin states are so similar, our conclusions concerning binding energies appear to be robust.

We first consider gas phase predictions. Table $\Pi$ depicts the PBE, B3LYP, and DFT $+\mathrm{U}$ results based on the PBE functional and $U=4.2 \mathrm{eV}, J=1.0 \mathrm{eV}$. Here we use the notation $m$ to denote the magnetic moment of the entire complex in the simulation cell. 


\begin{tabular}{lrrrrr}
\hline Species & Ligand & $m$ & \multicolumn{4}{r}{ PBE } & B $3 L Y P$ & DFT+U \\
\hline $\mathrm{Mn}(\mathrm{II}) \mathrm{P}$ & $\mathrm{NO}$ & 0 & -2.031 & -0.524 & -0.607 \\
$\mathrm{Mn}(\mathrm{II}) \mathrm{P}$ & $\mathrm{NO}$ & 1 & -1.687 & -0.728 & -0.930 \\
$\mathrm{Mn}(\mathrm{II}) \mathrm{P}$ & $\mathrm{NO}$ & 2 & $\mathrm{NA}$ & -0.022 & -0.407 \\
\hline $\mathrm{Mn}(\mathrm{III}) \mathrm{P}$ & $\mathrm{NO}$ & $1 / 2$ & -1.302 & $0.000^{*}$ & $+0.030^{*}$ \\
$\mathrm{Mn}(\mathrm{III}) \mathrm{P}$ & $\mathrm{NO}$ & $3 / 2$ & -0.651 & -0.322 & -0.401 \\
$\mathrm{Mn}(\mathrm{III}) \mathrm{P}$ & $\mathrm{NO}$ & $5 / 2$ & -0.103 & -0.077 & -0.163 \\
\hline $\mathrm{Mn}(\mathrm{II}) \mathrm{P}$ & $\mathrm{H}_{2} \mathrm{O}$ & $5 / 2$ & $\mathrm{NA}$ & -0.359 & -0.345 \\
$\mathrm{Mn}(\mathrm{II}) \mathrm{P}$ & $\mathrm{H}_{2} \mathrm{O}$ & $3 / 2$ & -0.283 & $\mathrm{NA}$ & $\mathrm{NA}$ \\
\hline $\mathrm{Mn}(\mathrm{II}) \mathrm{P}$ & $2 \mathrm{H}_{2} \mathrm{O}$ & $5 / 2$ & $\mathrm{NA}$ & -0.487 & -0.516 \\
$\mathrm{Mn}(\mathrm{II}) \mathrm{P}$ & $2 \mathrm{H}_{2} \mathrm{O}$ & $3 / 2$ & -0.457 & $\mathrm{NA}$ & $\mathrm{NA}$ \\
\hline $\mathrm{Mn}(\mathrm{II}) \mathrm{P}$ & $\mathrm{NO}+\mathrm{H}_{2} \mathrm{O}$ & 1 & $\mathrm{NA}$ & $\mathrm{NA}$ & -0.886 \\
$\mathrm{Mn}(\mathrm{II}) \mathrm{P}$ & $\mathrm{NO}+\mathrm{H}_{2} \mathrm{O}$ & 0 & -2.309 & $\mathrm{NA}$ & $\mathrm{NA}$ \\
\hline $\mathrm{Mn}(\mathrm{III}) \mathrm{P}$ & $\mathrm{H}_{2} \mathrm{O}$ & 2 & -0.571 & -0.629 & -0.581 \\
\hline $\mathrm{Mn}(\mathrm{III}) \mathrm{P}$ & $2 \mathrm{H}_{2} \mathrm{O}$ & 2 & -0.997 & -1.045 & -0.946 \\
\hline $\mathrm{Mn}(\mathrm{III}) \mathrm{P} \mathrm{NO}+\mathrm{H}_{2} \mathrm{O}$ & $3 / 2$ & $\mathrm{NA}$ & $\mathrm{NA}$ & -0.590 \\
$\mathrm{Mn}(\mathrm{III}) \mathrm{P} \mathrm{NO}+\mathrm{H}_{2} \mathrm{O}$ & $1 / 2$ & -1.854 & $\mathrm{NA}$ & $\mathrm{NA}$ \\
\hline
\end{tabular}

TABLE I: Binding energies between $\mathrm{MnP}$ and $\mathrm{NO}$ or $\mathrm{H}_{2} \mathrm{O}$, in $\mathrm{eV}^{44} \mathrm{PBE}$ and $\mathrm{DFT}+\mathrm{U}$ results utilizes planar wave basis while B3LYP calculations are performed using the 6$311+(\mathrm{d}, \mathrm{p})$ basis. $m$ is the total magnetic polarization in the complex. In some cases only the results for the most stable spin state predicted for each DFT functional are listed. ${ }^{*}$ Negligible binding energy predicted.

\section{A. $\mathrm{Mn}(\mathrm{II}) \mathrm{P}-\mathrm{NO}$}

PBE correctly predicts a low spin ground state for $\mathrm{Mn}(\mathrm{II}) \mathrm{P}-\mathrm{NO}$, with a $1.617 \AA \mathrm{Mn}-\mathrm{N}$ (nitric oxide) bond length, and a Mn-N-O angle of $173.6^{\circ}$. The Mn ion is displaced $0.342 \AA$ out of the porphine plane, and the porphine ring shows little evidence ofo non-planar deformation $(\sim 0.1 \AA$, see Table S4). These predictions are in good agreement with the $\mathrm{X}$-ray structure for nitrosyl $(5,10,15,20$-tetratolylporphinato $)$ manganese $(\mathrm{Mn}(\mathrm{TTP}) \mathrm{NO})$, which reveals a $1.641 \AA \mathrm{M}-$ NO bond length, a $177.8^{\circ} \mathrm{M}-\mathrm{N}-\mathrm{O}$ angle, and a $0.337 \AA$ Mn out-of-plane displacement $\underline{8.26 .27}$ The four other $\mathrm{Mn}(\mathrm{II})$ tetraarylporphyrins in the $\mathrm{CCDC}$ are 6coordinated but show similar Mn-NO distances (1.645$1.680 \AA$ ). The average Mn-N(porphyrin) distance in the PBE structure of $\mathrm{Mn}(\mathrm{II}) \mathrm{P}-\mathrm{NO}$ is $2.022 \AA$, which compares favorably with the crystal structure distance of $2.004 \AA .26$ The crystal structure of Mn(II)TPP-NO also shows a modest amount of non-planar deformation $(\sim$ $1.2 \AA$, Table S5) which may in part explain the slightly shorter Mn-N (porphyrin distance. PBE predicts a large $(2.03 \mathrm{eV})$ MnP-NO binding energy (Table I).

$\mathrm{DFT}+\mathrm{U}$ and B3LYP results are qualitatively and even quantiatively similar to each other but disagree with the experimental data. They predict, incorrectly, that the $m=1$, intermediate spin configuration is more stable than the low spin state, by 0.20 and $0.32 \mathrm{eV}$, respec-
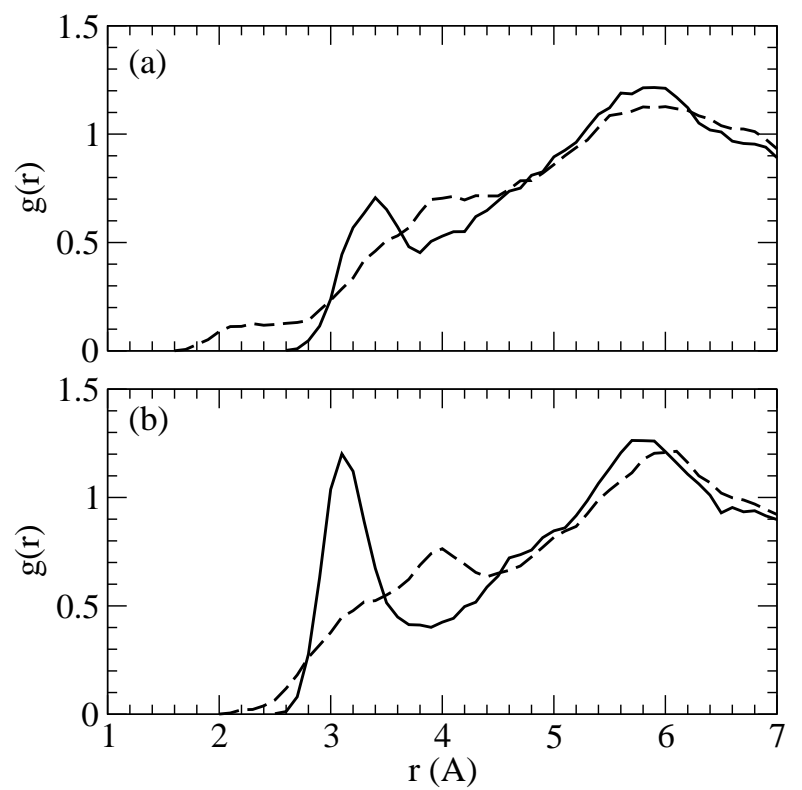

FIG. 5: Pair correlation functions, $g_{\mathrm{N}-\mathrm{O}_{\mathrm{w}}}(r)$ (solid lines) and $g_{\mathrm{N}-\mathrm{H}_{\mathrm{w}}}(r)$ (dashed lines), between the nitrogen atoms and the oxygen/hydrogen sites of $\mathrm{H}_{2} \mathrm{O}$ for (a) $\mathrm{Mn}(\mathrm{II}) \mathrm{P}$; (b) $\mathrm{Mn}(\mathrm{III}) \mathrm{P}$.

tively. For this ground state, the $\mathrm{Mn}-\mathrm{N}_{\mathrm{NO}}$ distance is $1.91(1.89) \AA$ the $\mathrm{Mn}-\mathrm{N}-\mathrm{O}$ angle is $142.2(144.2)^{\circ}$, the out-of-plane Mn displacement is $0.277(0.323) \AA$, and the MnP-NO binding energy is $0.93(0.73) \mathrm{eV}$. DFT $+\mathrm{U}$ further predicts that the low-spin configuration still exhibits a considerable binding energy of $0.61 \mathrm{eV}$, with a $1.766 \AA$ $\mathrm{Mn}-\mathrm{NO}$ bond length and $174^{\circ} \mathrm{M}-\mathrm{N}-\mathrm{O}$ bond angle, respectively.

We note that Gaussian B3LYP calculations reveal some spin-contamination for the $m=1$ intermediate spin state. The VASP package does not calculate spin contaminations, but it is likely that VASP-based $\mathrm{DFT}+\mathrm{U}$ calculations also contain a similar degree of spincontamination for this spin state. We emphasize that only the NO-ligated species exhibit such a contamination. Since both the energies of the $m=0$ and $m=1$ spin states agree to within $0.3 \mathrm{eV}$, the order of magnitude of our binding energies will likely not be strongly affected by the ambiguity regarding the spin state.

\section{B. $\mathrm{Mn}(\mathrm{III}) \mathrm{P}-\mathrm{NO}$}

To our knowledge, no X-ray structures for NO-ligated Mn(III) porphyrins exist. Such hypothetical systems would be $\{\mathrm{M}-\mathrm{NO}\}^{5}$ complexes, which in principle should exhibit a low-spin $(m=1 / 2)$, short $\mathrm{Mn}-\mathrm{N}_{\mathrm{NO}}$, linear Mn$\mathrm{N}-\mathrm{O}$ geometry: $\stackrel{26}{2} \mathrm{PBE}$ predicts such a low spin structure, but also yields an anomalously large MnP-NO binding energy of $1.30 \mathrm{eV}$ (Table [) see below). This structure has an out-of-plane Mn displacement of $0.36 \AA$, which is 


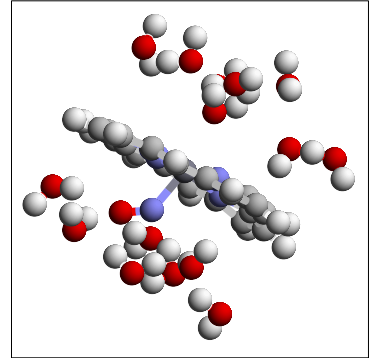

(a)

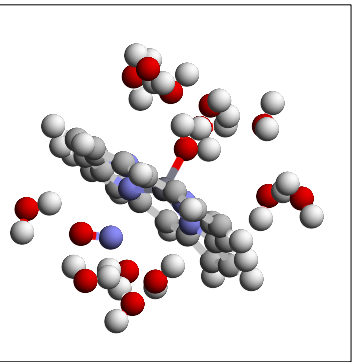

(b)
FIG. 6: Representative snapshots of (a) initial and (b) final configurations of the $\mathrm{Mn}(\mathrm{III}) \mathrm{P}-\mathrm{NO}$ complex in water after 0.1 ps. Only $\mathrm{H}_{2} \mathrm{O}$ molecules close to the $\mathrm{Mn}$ ion are depicted.

comparable to that seen for low spin $\mathrm{Mn}(\mathrm{II}) \mathrm{P}-\mathrm{NO}$.

Both DFT $+\mathrm{U}$ and B3LYP predict negligible binding energies for NO with low spin $\mathrm{Mn}$ (III)P. The $m=3 / 2$ intermediate spin configuration, on the other hand, yields a small binding energy of $0.40(0.32) \mathrm{eV}$ and a small outof-plane Mn displacement of 0.16 (0.10) Å. While no experimental data for binding energy is available, $\mathrm{DFT}+\mathrm{U}$ predicts that the $\mathrm{Mn}(\mathrm{III}) \mathrm{P}-\mathrm{H}_{2} \mathrm{O}$ complex is more favorable than the $\mathrm{Mn}(\mathrm{III}) \mathrm{P}-\mathrm{NO}$ complex, while the reverse is true for PBE. This suggests that $\mathrm{H}_{2} \mathrm{O}$ will displace $\mathrm{NO}$ in a $\mathrm{DFT}+\mathrm{U}$ based AIMD simulation, consistent with experiments on water-soluble $\mathrm{Mn}(\mathrm{III})$ porphyrins $\stackrel{2,3,4}{=} \mathrm{In}$ contrast, because of the strong binding energy with NO, AIMD simulations based on the PBE exchange correlation functional will likely not lead to $\mathrm{Mn}$ (III)P-NO dissociation in water $\underline{\underline{50}}$

Gaussian calculations again reveal some spincontamination for both the $m=1 / 2$ and $m=3 / 2$ states. In contrast, no spin-contamination is observed for either $\mathrm{Mn}(\mathrm{II}) \mathrm{P}$ or $\mathrm{Mn}(\mathrm{III}) \mathrm{P}-\mathrm{Cl} \underline{19}^{19}$ This underscores that MnP-NO systems are difficult to model using DFT methods.

\section{MnP-NO in water}

Next, we investigate the stability of MnP-NO complexes in liquid water by conducting AIMD simulations. We pre-equilibrate hydrated $\mathrm{Mn}(\mathrm{II}) \mathrm{P}-\mathrm{NO}$ configurations from a GCMC run as before, holding MnP-NO rigid in the $\mathrm{DFT}+\mathrm{U}$ optimized, intermediate spin configuration, and then conduct AIMD simulations for 3 ps. Unlike for $\mathrm{Mn}(\mathrm{II}) \mathrm{P}$ ligated to $\mathrm{H}_{2} \mathrm{O}$, the potential energy reaches a plateau on a sub-picosecond timescale. We find that the $\mathrm{Mn}$ ion in $\mathrm{Mn}(\mathrm{II}) \mathrm{P}-\mathrm{NO}$ complex is stable in water, and does not ligate to any additional $\mathrm{H}_{2} \mathrm{O}$ molecules.

Next, we consider $\mathrm{Mn}(\mathrm{III}) \mathrm{P}-\mathrm{NO}$ in water. Starting from an equilibrated aqueous $\mathrm{Mn}(\mathrm{II}) \mathrm{P}-\mathrm{NO}$ configuration (Fig. 1d), we remove an electron from the simulation cell, and restart the DFT $+\mathrm{U}$ based AIMD trajectory with the

\begin{tabular}{|c|c|c|c|c|}
\hline species & expt. & $\mathrm{PBE}$ & B3LYP & $\mathrm{DFT}+\mathrm{U}$ \\
\hline $\mathrm{Mn}(\mathrm{II}) \mathrm{P}$ & $s=5 / 2$ & no & yes & yes \\
\hline $\mathrm{Mn}(\mathrm{III}) \mathrm{P}$ & $s=2$ & yes & yes & yes \\
\hline $\mathrm{Mn}(\mathrm{II}) \mathrm{P}-\mathrm{NO}$ & $s=0$ & yes & no & no \\
\hline $\mathrm{Mn}(\mathrm{III}) \mathrm{P}-\mathrm{NC}$ & ility in water & no & NA & yes \\
\hline
\end{tabular}

TABLE II: Brief summary of the successes and failures of different DFT methods. Gas phase DFT and aqueous phase AIMD simulations that apply the same functional predict the same stable spin states in all cases considered.

spin polarization fixed at $m=3 / 2$. Within $0.1 \mathrm{ps}$, the $\mathrm{NO}$ diffuses away from the $\mathrm{Mn}(\mathrm{III})$ ion, replaced by an $\mathrm{H}_{2} \mathrm{O}$ from the other side of the porphine plane (Fig. 1e; Fig. 6). Thus, DFT $+\mathrm{U}$ predicts that $\mathrm{Mn}(\mathrm{III}) \mathrm{P}$ fails to bind to $\mathrm{NO}$ in water, in agreement with experiments. ${ }^{2}$

To examine PBE predictions for $\mathrm{Mn}(\mathrm{III}) \mathrm{P}-\mathrm{NO}$, we use a $\mathrm{DFT}+\mathrm{U}$ predicted $\mathrm{Mn}(\mathrm{III}) \mathrm{P}$ configuration in water, manually reposition the NO molecule to yield a $180^{\circ} \mathrm{Mn}$ $\mathrm{N}-\mathrm{O}$ angle and a $1.8 \AA \mathrm{Mn}-\mathrm{N}$ bond length, impose a low spin $(m=1 / 2)$ spin state, and restart the AIMD simulation using the PBE functional. We find that $\mathrm{Mn}(\mathrm{III}) \mathrm{P}$ NO complex is stable in water over the course of a $5 \mathrm{ps}$ trajectory. While these AIMD runs are short, their qualitative results are completely consistent with the relative stabiliy of $\mathrm{Mn}(\mathrm{III}) \mathrm{P}-\mathrm{NO}$ and $\mathrm{Mn}(\mathrm{III}) \mathrm{P}-\mathrm{H}_{2} \mathrm{O}$ based on gas phase binding energy considerations (Table \). They show that PBE predictions are in apparent disagreement with experiments: $2,3,51$

\section{Summary of MnP-NO interactions}

The apparent successes and failures of PBE and $\mathrm{DFT}+\mathrm{U}$ methods in the gas and liquid phases are summarized in Table III. Recall that, in the absence of the NO ligand, PBE predicts an incorrect, intermediate $\mathrm{Mn}(\mathrm{II}) \mathrm{P}(s=3 / 2)$ spin state while both B3LYP and $\mathrm{DFT}+\mathrm{U}$ parameterized with B3LYP spin splittings predict the correct high spin $(s=5 / 2)$ state $\frac{19}{19}$ All three methods predict the correct spin state for Mn(III)P (high spin, $s=2)$. The DFT $+\mathrm{U}$ method correctly predicts that the $\mathrm{Mn}$ (III)P-NO is unstable in liquid water. However, the spin state of the predicted stable species in the gas phase is inconsistent with the typical low-spin $\{\mathrm{M}-\mathrm{NO}\}^{5}$ structural parameters. PBE predicts that $\mathrm{Mn}(\mathrm{III}) \mathrm{P}-\mathrm{NO}$ is a strongly bound complex, in apparent disagreement with aqueous phase experiments. For the Mn(II)P-NO structure, $\mathrm{PBE}$ predicts the experimental structure and spin state, while B3LYP and DFT $+\mathrm{U}$ do not.

Both the hybrid functional B3LYP and the DFT $+\mathrm{U}$ method favor the high-spin states of first row transition metal ion, by increasing the exchange interaction or screened couloumb interaction among $3 d$ electrons. To a first approximation, when Mn and NO are far apart, 
enforcing $m=0$ on the $\mathrm{Mn}(\mathrm{II}) \mathrm{P}-\mathrm{NO}$ complex requires equal and opposite local $s=1 / 2$ spin moments on $\mathrm{Mn}$ and on the $\mathrm{N}$ atom of the NO molecule. We conjecture that DFT $+\mathrm{U}$ cannot reproduce the stability of $m=0$ $\mathrm{Mn}(\mathrm{II}) \mathrm{P}-\mathrm{NO}$ because $\mathrm{Mn}(\mathrm{II}) \mathrm{P}$ strongly favors the high spin $(m=5 / 2)$ state, while the low spin $(m=1 / 2)$ state is highly unfavorable. In contrast, in PBE calculations the $m=1 / 2$ state is not extremely unfavorable in energy compared to $m=3 / 2$, the stable $\mathrm{Mn}$ (II)P spin state erroneously predicted by $\mathrm{PBE}$. Therefore, at least when $\mathrm{Mn}(\mathrm{II}) \mathrm{P}$ and NO are far apart, PBE predictions more readily accommodates a $m=0$ spin state.

In summary, state-of-the-art DFT methods are as yet unable to capture the delicate balance of competing effects and correlations that determine the stable spin state of $\mathrm{Mn}(\mathrm{II}) \mathrm{P}, \mathrm{Mn}(\mathrm{III}) \mathrm{P}$, and their nitric oxide complexes. NO ligation seems to be especially challenging due to $\pi$ electron back bonding, ${ }^{28,29}$ The DFT $+\mathrm{U}$ method, with its most important parameter $U$ fitted to the $\mathrm{Mn}(\mathrm{II}) \mathrm{P}$ high spin-intermediate spin splitting, should be further improved to take into account such $\pi$-back bonding, $\underline{53}$ These improvements may allow the more accurate prediction of binding energies, which have not been addressed in recent DFT work on porphyrin-nitric oxide complexes $\stackrel{28.29}{\underline{2}}$

\section{CONCLUSIONS}

In this work, we have conducted ab initio molecular dynamics simulations of the hydration environment of the $\mathrm{Mn}$ ion in $\mathrm{Mn}$ (II)P and $\mathrm{Mn}(\mathrm{III}) \mathrm{P}$ dispersed in liquid water. These are intended as simple models of watersoluble manganese porphyrins. The $\mathrm{DFT}+\mathrm{U}$ technique, parameterized with B3LYP spin splittings, successfully predicts that high spin $\mathrm{Mn}(\mathrm{II}) \mathrm{P}$ and $\mathrm{Mn}(\mathrm{III}) \mathrm{P}$ are stable in liquid water. Thus, this technique enables efficient molecular dynamics simulation of $\mathrm{MnP}$ with the correct spin state in a condensed phase environment. In contrast, the B3LYP functional, with its long range exchange, is costly to apply when using periodic boundary conditions.

The $\mathrm{Mn}$ ion in $\mathrm{Mn}(\mathrm{II}) \mathrm{P}$ is predicted to displaced offcenter out of the porphine plane by an average of $0.48 \AA$, and is ligated to a single $\mathrm{H}_{2} \mathrm{O}$ molecule. The $\mathrm{Mn}$ ion in $\mathrm{Mn}(\mathrm{III}) \mathrm{P}$ is on average co-planar within the porphine plane and binds strongly to $2 \mathrm{H}_{2} \mathrm{O}$ molecules. Water molecules ligated to the $\mathrm{Mn}$ ion exhibit residence times of more than 15 ps. Water only interacts weakly with the nitrogen atoms on the porphine ring chelating the $\mathrm{Mn}$ ion. These predicted hydration structures might be potentially useful for improved analysis of NMR relax- ation data $\underline{\underline{10,11}}$

The application of DFT techniques to examine MnPNO binding in both gas and aqueous phases proves less successful than for $\mathrm{MnP}$ dispersed in water. Ideally, the DFT $+\mathrm{U}$ technique, fit to B3LYP spin splittings for $\mathrm{Mn}$ (II)P and found to be successful for unligated MnP, should be applicable to all ligated complexes as well. Indeed, we find that DFT $+\mathrm{U}$ apparently succeeds in describing the binding energy of the $\mathrm{Mn}(\mathrm{III}) \mathrm{P}-\mathrm{NO}$ complex. It predicts that the $\mathrm{Mn}(\mathrm{III}) \mathrm{P}-\mathrm{NO}$ binding energy is substantially smaller than that for $\mathrm{Mn}(\mathrm{III}) \mathrm{P}-\mathrm{H}_{2} \mathrm{O}$. AIMD based on the $\mathrm{DFT}+\mathrm{U}$ technique predicts a rapid dissociation of the $\mathrm{Mn}(\mathrm{III}) \mathrm{P}-\mathrm{NO}$ in water, consistent with the known instability of $\mathrm{Mn}(\mathrm{III}) \mathrm{P}-\mathrm{NO}$ in aqueous phase experiments. ${ }^{2.3}$ Both DFT $+\mathrm{U}$ and B3LYP predict significantly larger $\mathrm{Mn}$ (II)P-NO binding energies than for $\mathrm{Mn}$ (III)P-NO. This differential ability of $\mathrm{Mn}(\mathrm{II})$ and $\mathrm{Mn}$ (III) porphyrins to ligate to NO is crucial for detecting $\mathrm{NO}$ in water and distinguishing $\mathrm{NO}$ from $\mathrm{HNO}$ or $\mathrm{NO}^{-}$via electrochemical means. In contrast, $\mathrm{PBE}$ predicts large $(>0.8 \mathrm{eV}) \mathrm{Mn}-\mathrm{NO}$ binding energies for both $\mathrm{Mn}(\mathrm{II}) \mathrm{P}-\mathrm{NO}$ and $\mathrm{Mn}$ (III)P-NO, which would suggest, erroneously, that switching the oxidation state of $\mathrm{MnP}$ cannot trap and then release NO.

We emphasize that B3LYP and DFT $+\mathrm{U}$ predictions qualiltatively agree with each other regarding $\mathrm{Mn}(\mathrm{II}) \mathrm{P}-$ NO binding, despite the fact that the $\mathrm{DFT}+\mathrm{U}$ technique used herein is parameterized using B3LYP spin splitting for the bare $\mathrm{Mn}$ (II)P molecule. However, both these techniques predict incorrect spin states for the $\mathrm{Mn}(\mathrm{II}) \mathrm{P}-\mathrm{NO}$ complex. On the other hand, the PBE functional predicts a $\mathrm{Mn}(\mathrm{II}) \mathrm{P}-\mathrm{NO}$ low spin spin state and molecular geometry that are in good agreement with experiments.

While it is clear that more fundamental improvements to DFT methods need to be made, AIMD simulations based on the DFT $+\mathrm{U}$ technique successfully predicts many experimentally observed ligation features of $\mathrm{Mn}$ porphyrins, including the observation that complexes formed between $\mathrm{Mn}$ (III) porphyrins and nitric oxide are unstable in liquid water.

\section{Acknowledgements}

We thank John Shelnutt, Sameer Varma, and Prof. Robert Sharp for useful discussions. Sandia is a multiprogram laboratory operated by Sandia Corporation, a Lockheed Martin Company, for the U.S. Department of Energy's National Nuclear Security Administration under contract DE-AC04-94AL8500.
${ }^{1}$ Kadish, K. M.; Smith, K. M.; Guilard, R. The Porphyrin Handbook (Academic Press, San Diego, 2000).
${ }^{2}$ M. A. Marti, S. E. Bari, D. A. Estrin, and F. Doctorovich, 
J. Am. Chem. Soc. 127, 4680 (2005).

3 J. Oni, N. Diab, I. Radtke, and W. Schuhmann, Electrochimica Acta 48, 3349 (2003).

${ }^{4}$ I. Spasojevic, I. Batinic-Haberle, and I. Fridovich, Nitric Oxide: Biol. and Chem. 4, 526 (2000).

5 B. J. Vesper, K. Salaita, H. Zong, C. A. Mirkin, A. G. M. Barratt, and B. M. Hoffman, J. Am. Chem. Soc. 126, 16653 (2004).

6 S. Yoshimoto, J. Inukai, A. Tada, T. Abe, T. Morimoto, A. Osuka, H. Furuta, and K. Itaya, J. Phys. Chem. B 108, 1948 (2004)

7 Z. Wang, C. J. Medfoth, and J. A. Shelnutt, J. Am. Chem. Soc. 126, 16720 (2004).

8 W. R. Scheidt, K. Hatano, G. A. Rupprecht, and P. L. Piciulo, Inorg. Chem. 18, 292 (1979).

9 N. Schaefle and R. R. Sharp, J. Chem. Phys. 122, 184501 (2005).

10 J. C. Miller and R. Sharp, J. Phys. Chem. A 104, 4889 (2000).

11 L. H. Bryant, M. W. Hodges, and R. G. Bryant, Inorg. Chem. 38, 1002 (1999).

12 N. Schaefle and R. R. Sharp, J. Phys. Chem. A 109, 3267 (2005).

13 D. Asthagiri, L. R. Pratt, M. E. Paulaitis, and S. B. Rempe, J. Am. Chem. Soc. 126, 1285 (2004).

14 D. R. Nutt, M. Karplus, and M. Meuwly, J. Phys. Chem. B 109, 21118 (2005)

15 B. M. Rode, C. F. Schwenk, T. S. Hofer, and B. R. Randolf, Coord. Chem. Rev. 249, 2993 (2005).

16 M. Reiher, O. Salomon, and B. A. Hess, Theor. Chem. Acc. 107, 48 (2001); M. Reiher, Inorg. Chem. 41, 6928 (2002).

17 A. Ghosh and P. R. Taylor, Curr. Opin Chem. Biol. 7, 113 (2003).

18 A. D. Becke, J. Chem. Phys. 98, 5648 (1993); C. T. Lee, W. T. Yang, and R. G. Parr, Phys. Rev. B 37, 785 (1988).

19 K. Leung, S. B. Rempe, P. A. Schultz, E. M. Sproviero, V. S. Batista, M. E. Chandross, and C. J. Medforth, J. Am. Chem. Soc. 128, 3659 (2006).

20 J. P. Perdew, K. Burke, and M. Ernzerhof, Phys. Rev. Lett. 77, 3865 (1996).

21 Note that hybrid functionals such as B3LYP are not universally more successful than non-hybrid ones like PBE. A counter example is the case of transition metal dimers. See N. E. Schultz, Y. Zhao, D. G. Truhlar, J. Phys. Chem. A 109, 4388 (2005) and references therein.

${ }^{22}$ H. J. Kulik, M. Cococcioni, D. A. Scherlis, and N. Marzari, http://arXiv.org/cond-matt/0608285 (2006)

23 The four negatively charged sulfonate groups in MnTSPP ensure that the $\mathrm{Mn}$ ion is not ligated to anions in aqueous solutions, even if it is in the +3 oxidation state; hence we do not consider counter ions when modeling $\mathrm{Mn}(\mathrm{III}) \mathrm{P}$ in liquid water.

24 V. I. Anisimov, J. Zaanen, and O. K. Andersen, Phys. Rev. B, 44, 943 (1991); A. I. Liechtenstein, A. I. Anisimov, and J. Zaanen, Phys. Rev. B 52, 5467 (1995).

25 Y. Tateyama, J. Blumberger, M. Sprik, and I. Tavernelli, J. Chem. Phys. 122, 234505 (2005).

${ }^{26}$ G. R. A. Wyllie and W. R. Scheidt, Chem. Rev. 102, 1067 (2002), and references therein.

27 Z. N. Zahran, J. Lee, S. S. Alguindigue, M. A. Khan, and
G. B. Richter-Addo, Dalton Trans. 44 (2004).

${ }^{28}$ K. M. Vogel, P. M. Kozlowski, M. Z. Zgierski, and T. G. Spiro, J. Am. Chem. Soc. 121, 9915 (1999).

29 T. Wondimagegn and A. Ghosh, J. Am. Chem. Soc. 123, 5680 (2001).

30 O. Bengone, M. Alouani, P. Blöchl, and J. Hugel, Phys. Rev. B, 62, 16392 (2000).

31 G. Kresse and J. Furthmüller, Phys. Rev. B 54, 11169 (1996); Comput. Mater. Sci. 6, 15 (1996).

32 P. E. Blochl, Phys. Rev. B, 50, 17953 (1994); for VASP implementation, see G. Kresse and D. Joubert Phys. Rev. B 59, 1758 (1999)

33 D. Asthagiri, L. R. Pratt, J. D. Kress, Phys. Rev. E 68, 415051 (2003); J. C. Grossman, E. Schwegler, E. W. Draeger, F. Gygi, G. Galli, J. Chem. Phys. 120, 300 (2004); J. VandeVondele, F. Mohamed, M. Krack, J. Hutter, M. Sprik, M. Parrinello, J. Chem. Phys. 122, 014515 (2005).

34 M. G. Martin and A. P. Thompson, Fluid Phase Equil. 217, 105 (2004).

35 H. J. C. Berendsen, J. R. Gridera, and T. P. Straatsma, J. Phys. Chem. 91, 6269 (1987).

36 X.-Z. Song, L. Jaquinod, W. Jentzen, D. J. Nurco, S.-L. Jia, R. G. Khoury, J.-G. Ma, C. J. Medforth, K. M. Smith, and J. A. Shelnutt, Inorg. Chem. 37, 2009 (1998); J. A. Shelnutt, C. J. Medforth, M. D. Berber, K. M. Barkigia, and K. M. Smith, J. Am. Chem. Soc. 113, 4077 (1991).

37 Z.-W. Zhou, B. D. Todd, K. P. Travis, and R. J. Sadus, J. Chem. Phys. 123, 054505 (2005).

38 M. J. Frisch, et al., Gaussian 03 (Revision C.02), Gaussian Inc., (Wallingford, CT, 2004).

39 D. Asthagiri and L. R. Pratt, Chem. Phys. Lett. 371, 613 (2003).

40 Z. Luz and R. G. Shulman, J. Chem. Phys. 43, 3750 (1965); R. A. Bernhein, T. H. Brown, H. S. Gutowsky, and D. E. Woessner, J. Chem. Phys. 30, 950 (1959).

41 P. H.-L. Sit and Ni. Marzari, J. Chem. Phys. 122, 204510 (2005).

42 E. Schwegler, J. C. Grossman, F. Gygi, and G. Galli, J. Chem. Phys. 121, 5400 (2004).

43 K. Leung and S. B. Rempe, Phys. Chem. Chem. Phys. 8, 2153 (2006).

44 These energies do not include zero point energy (ZPE) corrections. We have not computed ZPE for MnP, but we note that the FeP-NO vibration frequency has been shown to be small, on the order of $550 \mathrm{~cm}^{-1}, 28$ which implies a ZPE of at most $2 \mathrm{kcal} / \mathrm{mol}$.

45 J. F. Kirner, C. A. Reed, W. R. Scheidt, J. Am. Chem. Soc. 99, 1093 (1977).

46 B. Cheng, W. R. Scheidt, Acta Crystallogr. C. 52, 361 (1996).

47 P. Turner, M. J. Gunter, B. W. Skelton, A. H. White, and T. W. Hambley, J. Chem. Res. 18, 220 (1996).

48 Indeed, our preliminary PBE based AIMD simulations, with the simulation cell constrained to $m=5 / 2$, show that PBE predicts a much higher tendency towards Mn(II) binding to two water molecules, and the $\mathrm{Mn}$ (II) ion residing in the porphine plane.

49 See, e.g., K. Leung, Biophys. Chem. (in press).

50 To make this point more precise, note that the previous 
section shows that $\mathrm{Mn}(\mathrm{III}) \mathrm{P}$ binds to two $\mathrm{H}_{2} \mathrm{O}$ in liquid water. Therefore we should compare the $\mathrm{PBE}$ energies of $\mathrm{Mn}(\mathrm{III}) \mathrm{P}(\mathrm{NO})\left(\mathrm{H}_{2} \mathrm{O}\right)$ and $\mathrm{Mn}(\mathrm{III}) \mathrm{P}\left(\mathrm{H}_{2} \mathrm{O}\right)_{2}$. Table I indicates that that, in the gas phase, the former is more favorable by $0.857 \mathrm{eV}$, or $19.75 \mathrm{kcal} / \mathrm{mol}^{44}$ This is an underestimate of the energetic preference for $\mathrm{Mn}(\mathrm{III}) \mathrm{P}(\mathrm{NO})\left(\mathrm{H}_{2} \mathrm{O}\right)$ in liquid water, because replacing a $\mathrm{NO}$ ligand with $\mathrm{H}_{2} \mathrm{O}$ from the bulk water region involves breaking two hydrogen bonds and moving a hydrophobic species (NO) into bulk water. At $\mathrm{T}=300 \mathrm{~K}$, one can readily estimate that the translational entropy advantage of dissociating $\mathrm{Mn}(\mathrm{III}) \mathrm{P}-$ $\mathrm{NO}$ in a $1 \mu \mathrm{M}$ NO solution is $\sim 11 \mathrm{kcal} / \mathrm{mol}$. This entropic gain is too small to offset the binding energy cost for dissociation. Thus, by any reasonable measure, PBE erroneously predicts that the $\mathrm{Mn}(\mathrm{III}) \mathrm{P}(\mathrm{NO})$ complex does not dissociates in liquid water.

51 The dynamics of dissociation can be extremely complex and may involve spin-forbidden transitions. ${ }^{52}$ Studying
$\mathrm{Mn}(\mathrm{II}) \mathrm{P}-\mathrm{NO}$ dissociation is not the main objective of this work.

52 J. N. Harvey, J. Am. Chem. Soc. 122, 12401 (2000).

${ }^{53}$ We have not found values of $U$ within the DFT+U approach that yield both a high spin ground state for $\mathrm{Mn}(\mathrm{II}) \mathrm{P}$ and a low spin ground state for $\mathrm{Mn}(\mathrm{II}) \mathrm{P}-\mathrm{NO}$. This suggests that dynamic electronic correlation effects, not accounted for by the static DFT $+\mathrm{U}$ method, may be important in $\mathrm{Mn}(\mathrm{II}) \mathrm{P}-\mathrm{NO}$.

54 See EPAPS Document No. XXXX for supplemental information on normal-coordinate structure decomposition (NSD) analysis of several computed and experimental porphyrin structures. This document may be retrieved via the EPAPS homepage (http://www.aip.org/pubservs/epaps.html) or from ftp.aip.org in the directory /epaps/. See the EPAPS homepage for more information. 